\title{
Effect of torch process on the steels used for bucket, shovel handle, and other high- tonne mining equipment
}

\author{
H. Ochoa Medina ${ }^{1,2}$, J. Leiva Yapur ${ }^{1,3}$, O. Fornaro ${ }^{4,5^{*}}$ (D) and Z. Cárdenas Quezada ${ }^{1}$
}

\begin{abstract}
Background: The gouging torch process using air carbon arc cutting (CAC) device is a standard maintenance procedure carrying out in high-tonne equipment used in the minery industry. The application of this process could locally affect the mechanical properties and the microstructure in the thermally affect zone (HAZ). The changes involve variation in the local carbon concentration and a tempering effect. In commonly used steels in the manufacture of buckets (SAE 5130) and shovel handles (ASTM 514 grade S), the processes influence negatively the work lifetime and the future maintenance works on the device.
\end{abstract}

Methods: Hardness, metallographic analysis trhough optical (OM) and scanning electron microscopy (SEM) were used to evaluate the affected zone.

Results: An increasing carbon content up to 2 wt\% C was observed in the affected area of the sample, on the slag adhered to it. Presumably, the rest of carbon is lost by evaporation during the process.

Conclusions: The hardness measured on the surface of the cut zone shows an increased value for ASTM A 514 grade $\mathrm{S}$, which does not present a notable change for SAE 5130. However, both steels showed a tempering effect. Microcracks of 20 to $40 \mu \mathrm{m}$ appear, and in a few opportunities, a larger crack was found, reaching a total length of $1480 \mu \mathrm{m}$.

Keywords: Air carbon arc cutting, Heavy equipment, High-strength steels

\section{Background}

In the air carbon arc cutting (CAC) process, the molten metal generated by the electric arc is swept off by a strong dry airflow rate of 700 to $1000 \mathrm{l} / \mathrm{min}$ and a working pressure up to $6 \mathrm{~kg} / \mathrm{cm}^{2}$. The electric arc is generated by a graphite electrode (typically $90 \% \mathrm{C}$ ) with other metallic elements $(\mathrm{Cu}, \mathrm{Ni}, \mathrm{Fe}$, among others). The composition is chosen to facilitate the passage of current and to avoid corrosion of the sample due to the pressurized air (American Society of Heating 2011; Victor Technologies, Inc. 2013; Varkey et al. 2013; Gutiérrez 2006; IS 1979; U.S. Department of Transportation 1994; AWS 1980; Das and Abarna 2015). The most common uses of this technique are (a)

\footnotetext{
* Correspondence: ofornaro@exa.unicen.edu.ar

${ }^{4}$ Instituto de Física de Materiales Tandil, IFIMAT (UNCPBA), Buenos Aires, Argentina

${ }^{5}$ Centro de Investigaciones en Física e Ingeniería del Centro de la Provincia de Buenos Aires, CIFICEN (UNCPBA-CICPBA-CONICET), Pinto 399, B700GHG Tandil, Argentina

Full list of author information is available at the end of the article
}

preparations of welded joints, (b) removal of welding defects, and (c) removal of welding and joints of structures.

During the application of the CAC gouging torch process, it is possible to cause damage to the steel base substrate of the mining equipment, due to the high temperatures involved in the process, which can easily reach $2000{ }^{\circ} \mathrm{C}$ in the molten metal. At first, thermal fluctuations so as the addition of carbon concentration may cause effects on the thermally affected zone (HAZ) (Tingaev et al. 2016; Andrés et al. 2016), which may include residual stresses (Yilbas and Arif 2011; Michaleris 1999; Hu et al. 2007; Kyong-Ho and Lee 2007; Ma et al. 2016) and subsequently generate fatigue in the material (Goldberg 1978; Ramaswamy 1989; Cicero et al. 2017; Liu et al. 2016; Zhang et al. 2016; ASM 2013; Lara et al. 2013) or even spontaneous fracture, starting from micro-crack formation. It is also possible to suppose that solid-solid phase transformations so as micro-structure 
Table 1 Chemical composition of the used steels

\begin{tabular}{lll}
\hline $\begin{array}{l}\text { Chemical } \\
\text { component }\end{array}$ & ASTM 514 grade S & SAE 5130 \\
\hline $\mathrm{C}$ & Wt\% of component & \\
$\mathrm{Si}$ & 0.167 & 0.268 \\
$\mathrm{Mn}$ & 0.358 & 0.249 \\
$\mathrm{P}$ & 1.166 & 0.975 \\
$\mathrm{~S}$ & $<0.003$ & $<0.003$ \\
$\mathrm{Cr}$ & $<0.003$ & $<0.003$ \\
$\mathrm{Ni}$ & 0.0067 & 0.0067 \\
$\mathrm{Mo}$ & 0.0098 & 0.057 \\
$\mathrm{Al}$ & 0.118 & 0.036 \\
$\mathrm{Ti}$ & 0.0038 & 0.063 \\
$\mathrm{~W}$ & 0.0012 & 0.0048 \\
$\mathrm{Fe}$ & $<0.02$ & $<0.02$ \\
\hline
\end{tabular}

changes take place into the affected area during the cooling after the process end.

In maintenance work, a direct relationship between zones that have been treated through torching gauging processes and failure fractures due to fatigue or embrittlement has been found. For companies engaged in the minery industry, the recovery of abrasion-worn parts and the elimination of deteriorated areas in the mining equipment occupied in the extraction of high tonnage are extremely important.

The aim of this work is to study how the maintenance that uses CAC gouging torch process affects the microstructural behavior and mechanical properties in the most commonly used SAE 5130 and ASTM 514 S grade steels used in the manufacture of high-tonne mining equipment.

\section{Methods}

\section{Used material}

The samples were extracted from out-of-service equipment. The commonly used steels are ASTM 514 grade $S$ for bucket and SAE 5130 in the case of shovel handles. The samples were initially cut with a Leco MSX255M saw equipment. After that, torch cuts were performed under ANSI/AWS C5.3-91 standard (Christensen 1973; Hause 1980; Panter 1977; Ridal 1977; Marshall 1980).

\section{Determination of chemical composition}

The steel samples were pickled with $\mathrm{SiC} 60$ paper, washed with distilled water, cleaned with acetone, washed again with bi-distilled water, and dried at room temperature prior to analysis. The determination was performed according to ASTM E 415-E 1806, on a Bruker Q2 Ion spectrometer. The results obtained are presented in Table 1.

\section{Determination of carbon in the slag}

The slag is formed by small drops of molten and solidified steel in contact with the substrate material. Generally, it is joined with the exposed surface and could be easily removed by mechanics means. In other situations, it is expelled from the working zone by the high-pressure air flux. The carbon content in this residue was determined using a Primus Rigaku X-ray fluorescence device on milled slag particles. At least three determinations were made for each sample, taking the average of the obtained values.

\section{Metallographic preparation and analysis}

The metallographic analysis was performed according to ASTM E-3 standard. The specimens were prepared with a careful mechanical polishing, using graduated $\mathrm{SiC}$ paper of 240, 340, 400, and 600 grades, cooled in all cases with water. The polishing was finished with an alumina solution $\left(\mathrm{Al}_{2} \mathrm{O}_{3}\right)$ in water on soft cloth. The microstructure was revealed by chemical etching by using nital (3\%) for 2-s intervals. Optical micrographs were performed with an Optika Microscope model XD$3 \mathrm{MET}$ at $500 \times$ and $1000 \times$. Electron microscopy images were taken with a scanning electron microscope JEOL model JSM-6360 LV, under the standard ASTM E 1508.

\section{Results and discussion}

As were previously said, during the cut process, part of the material is melted by the effect of an electric arc. Since the chemical composition of the electrode is rich in carbon, it

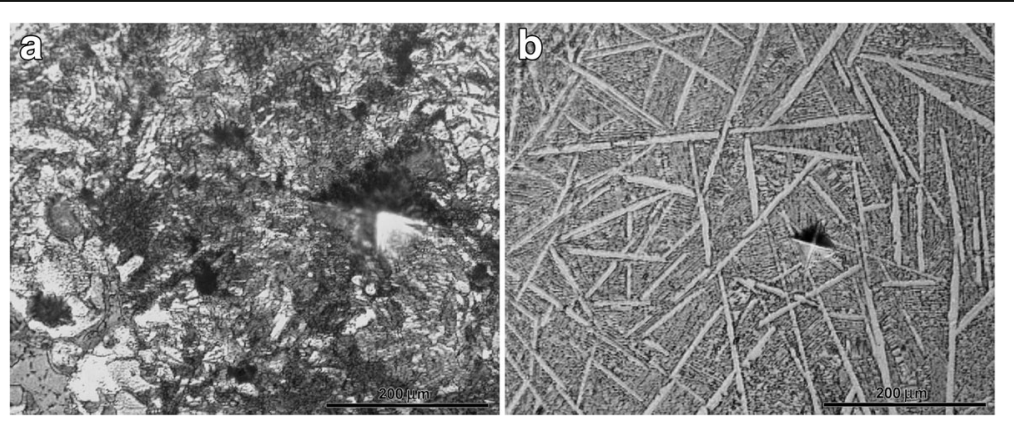

Fig. 1 Microstructure in different zones of the slag material of ASTM 514 grade S. a Austenitic zone. b Ferrite + carbides 


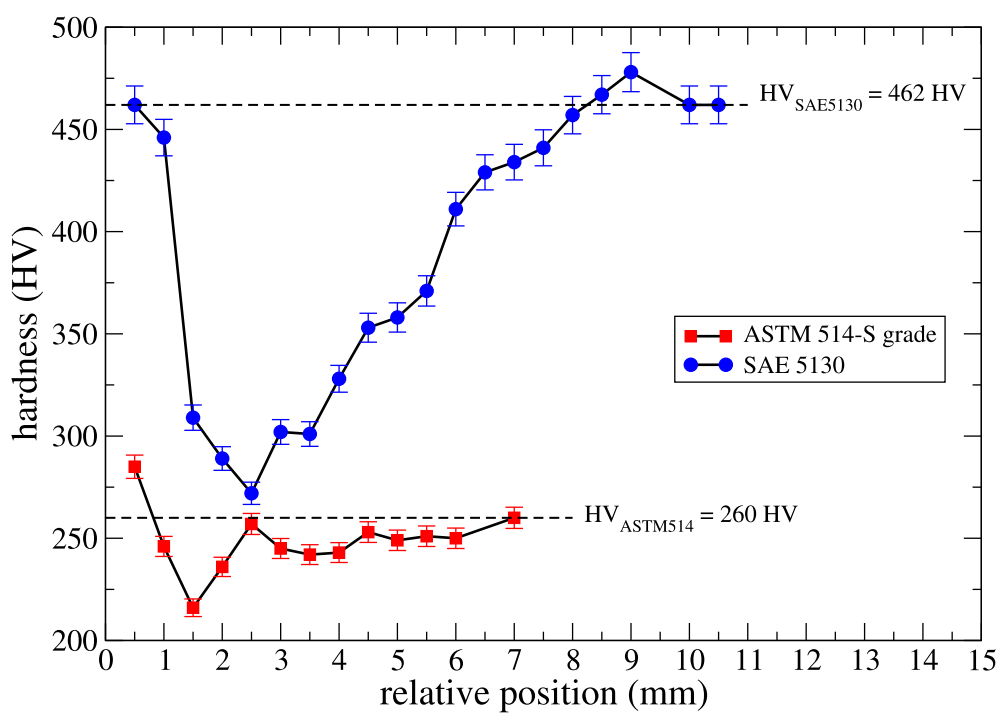

Fig. 2 Hardness and microhardness measured into the affected zone for both steels

can happen that the bath modifies its composition increasing the original solute carbon content. If this happens, a change in the microstructure would be more likely to occur, not only because of the high temperatures involved but also because of the diffusion of $\mathrm{C}$ in the liquid steel in the bath where the cutting takes place. For this reason, it is

Table 2 Microhardness profile measured in treated steel SAE 5130 post-torching

\begin{tabular}{ll}
\hline $\begin{array}{l}\text { Relative position } \\
\text { (See text) }(\mathrm{mm})\end{array}$ & $\begin{array}{l}\text { SAE } 5130 \\
(\mathrm{HV})\end{array}$ \\
\hline 0.5 & 462 \\
1 & 446 \\
1.5 & 309 \\
2 & 289 \\
2.5 & 272 \\
3.0 & 302 \\
3.5 & 301 \\
4.0 & 328 \\
4.5 & 353 \\
5.0 & 358 \\
5.5 & 371 \\
6.0 & 411 \\
6.5 & 429 \\
7.0 & 434 \\
7.5 & 441 \\
8.0 & 457 \\
8.5 & 467 \\
9.0 & 478 \\
10 & 462 \\
10.5 & 462 \\
\hline
\end{tabular}

interesting to know the composition of both the extracted material and the remnant in the piece, as part of the discussion related to the effects of the torch process.

As a first step, the composition of the material that comes out as slag from the cut is checked. This material is in principle liquid steel whose composition can be modified by the chemical elements that compose the electrode and that is solidified very quickly by the effect of the gas at high speed and pressure that extracts it from the bath generated once produced. The carbon content in these slag samples is higher than the original steel in both cases studied. For SAE 5130 steel, the C content determined in the slag was $1.69 \mathrm{wt} \% \mathrm{C}$, while for ASTM 514 grade S, a value of 1.93 wt\% C was obtained. In Fig. 1, the microstructure obtained for ASTM

Table 3 Idem for and ASTM A 514 grade S

\begin{tabular}{ll}
\hline $\begin{array}{l}\text { Relative position } \\
(\text { see text) }(\mathrm{mm})\end{array}$ & $\begin{array}{l}\text { ASTM } 514 \\
(\mathrm{HV})\end{array}$ \\
\hline 0.5 & 285 \\
1 & 246 \\
1.5 & 216 \\
2.0 & 236 \\
2.5 & 257 \\
3.0 & 245 \\
3.5 & 242 \\
4.0 & 243 \\
4.5 & 253 \\
5.0 & 249 \\
5.5 & 251 \\
6.0 & 250 \\
7.0 & 260 \\
\hline
\end{tabular}




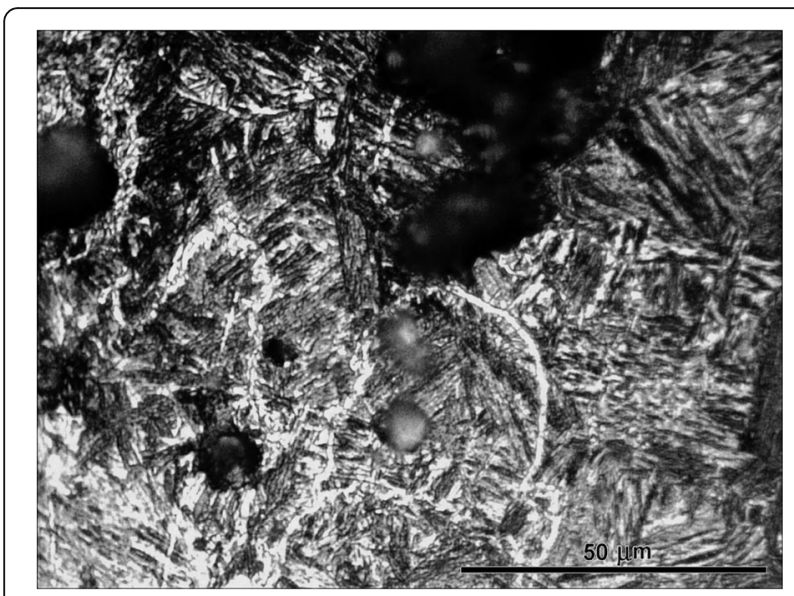

Fig. 3 Optical micrograph of SAE 5130 post-torching. Widmanstatten ferrite and martensite and some porosities could be observed

514 grade $\mathrm{S}$ ejected slag is shown in two different zones. Figure 1a corresponds to an austenitic structure, while Fig. 1b shows a microstructure of zone of high densities of needle carbides, consistent with a highcomposition steel.

The microhardness is a reflect of the different structures. The obtained values fluctuate between $677 \mathrm{HV}$ in the austenitic zone with dispersed carbides of Fig. 1a and $793 \mathrm{HV}$ in the sample of Fig. 1b. The high dispersion in the structures could be derived from the different local cooling conditions, size of the slag drops, and other considerations during the application of the $\mathrm{CAC}$ procedure.

In the case of ASTM 514 grade S steel sample, rodlike and laminar carbides were found in the microstructure of the slag. Note that since the evaporation temperature of the graphite is $4827{ }^{\circ} \mathrm{C}$, which is very close to the temperature that is reached at the electrode tip in the order of $5000-8000{ }^{\circ} \mathrm{C}$, whereby the graphite of the electrode will evaporate, generating a reduction atmosphere near the cutting zone. While this gas is partially removed by pressurized air, carbon-rich areas could occur on the surface. In addition, the molten steel can facilitate the graphite entry since the temperature is higher enough to maintain the liquid bath for a short time. This allows the mixture of gas enriched with the steel to be produced by a diffusion mechanism through the gas + liquid interface, allowing the precipitation of carbides.

Figure $1 \mathrm{~b}$ shows the typical dendritic microstructure of a foundry found in the cutting residue. The eutectic reaction $\mathrm{L} \rightarrow \mathrm{\gamma}+\mathrm{MC}$, together with the austenite, is evidenced in the observed structure. The formation of MC nuclei is originally in the form of sticks, later branching. Growth is in conjunction with austenite as the temperature decreases (Bochnowski et al. 2003, Yang et al. 2006, Hetzner and Geertruyden 2008, Luan et al. 2010).

The behavior of bulk material is of course of great interest. As a consequence of the high temperature of the CAC gouging torch process, a softening effect can be observed in the HAZ. The dimension of this zone is quite well defined and is a consequence of the thermal and geometric characteristics of the treated elements. This behavior can be observed by microhardness on a profile that begins on the outer surface of the sample and is directed towards the center of the same. The microhardness of unmodified SAE 5130 steel was $462 \mathrm{HV}$ and for ASTM 514 grade S steel $260 \mathrm{HV}$. These values were taken in areas far enough away from the cutting zone and will be used as a reference for the analysis that follows. In principle, the surface hardness taken on the cutting zone does not show a substantive difference with the reference value. A little increasing was noted on ASTM 514 grade S, prior to decrease, and shows a softening starting from the $500 \mu \mathrm{m}$ of depth. This effect of tempering has a depth that varied in each case, as can be seen in more detail in Fig. 2. The obtained values of hardness and microhardness in the profile are detailed in Tables 2 and 3.

As can be seen in Fig. 2, the HAZ area in the case of SAE 5130 can reach approximately $9 \mathrm{~mm}$ in depth. In this zone, the observed microstructure corresponds to martensitic type with a large number of Widmanstattentype needles, as can be seen in Fig. 3.
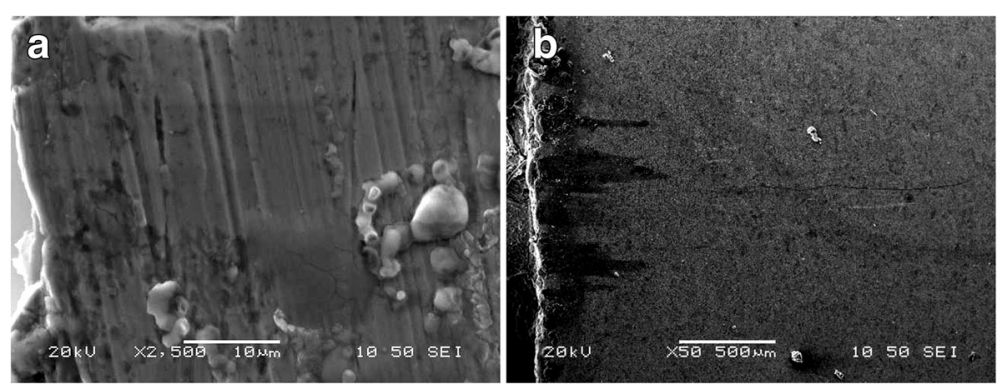

Fig. 4 SEM micrographs of SAE 5130 steel, adjacent to cutting zone, showing a the apparition of micro-cracks and $\mathbf{b}$ deep crack that reach the bulk material 


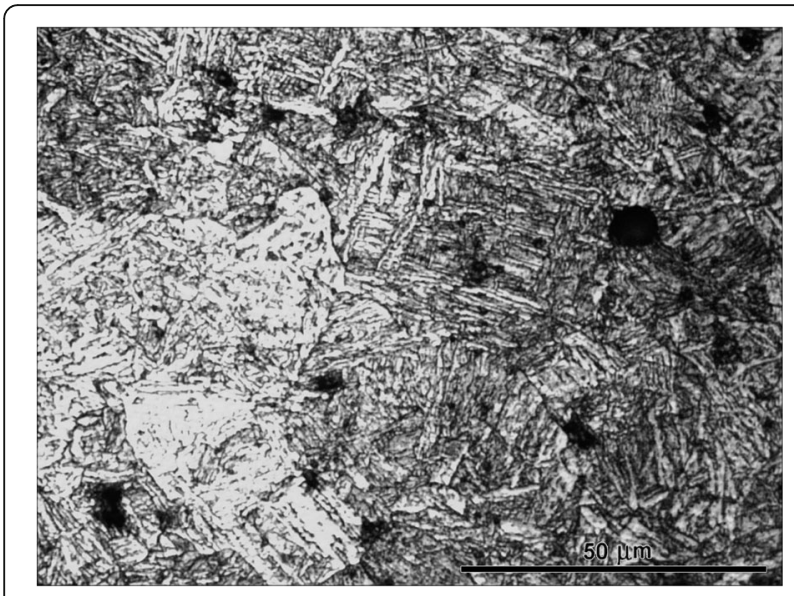

Fig. 5 Optical micrograph of ASTM 514 grade S post-torching

The reduction of the microhardness could be a consequence of a tempering caused by a high temperature delivered by the heat energy delivered by the torch. As can be seen in the SEM images of Fig. 4 for SAE 5130 steel, in the zone close to the surface, fissures of the order of $20 \mu \mathrm{m}$ are observed in the micrographs, although some may agglomerate to form larger cracks, several $\mathrm{mm}$ in length $(1500 \mu \mathrm{m})$.

On the other side, the ASTM 514 grade $S$ steel shows a small increase in surface hardness after the torch process, reaching a surface hardness of $285 \mathrm{HV}$. This value is an increase of approximately $10 \%$ with respect to the original value of $260 \mathrm{HV}$ determined far away from the cutting zone. This increase was found within the $500 \mu \mathrm{m}$ closest to the cut. As in the previous case, after this zone, a softening occurs in the interior of the sample, although the magnitude of the zone affected by heat is rather narrower than for the other steel, since in approximately $3 \mathrm{~mm}$, it recovers practically the original mechanical behavior.

In the affected zone, the observed microstructure is martensitic, with ferrite Widmanstatten as shown in Fig. 5. Also, a large amount of porosity and microcracks of approximately $50 \mu \mathrm{m}$ in length are found as can be seen in the scanning electron micrographs of Fig. 6 .

The observed behavior was similar to the reported in the bibliography for other thermal cutting methods. For example, after application of oxyfuel, laser, and plasma cutting, in the samples of S460 M steel, an increase in the superficial hardness followed by a decreasing in the mechanical properties was reported (Andrés et al. 2016). Also, for S345 and S390 steels treated by oxyfuel and plasma, cutting was found with similar results after being subjected to thermal cutting (Tingaev et al. 2016).

\section{Conclusions}

The analysis of the hardness and the observed microstructure shows that the torch process influences the behavior of the parts to be repaired, affecting the mechanical properties of the area. Formation of microcracks and porosities was also observed due to the same process.

The carbon content of the substrate material shows a small increment, apparently affected by the roasting process. Also, the $\mathrm{C}$ content is increased in the residue, reaching values close to $2 \mathrm{wt} \% \mathrm{C}$.

In the bulk material, the SAE 5130 steel shows microcracks less than $20 \mu \mathrm{m}$ in length and also some greater fissures up to $1480 \mu \mathrm{m}$. In the ASTM 514 grade $S$ steel, formation of microcracks of up to $40 \mu \mathrm{m}$ in length was observed, but not a greater scale fissuration.

In all cases, a surface hardness increase tendency was observed both for SAE 5130 as for ASTM 514 steels, up to a $500 \mu \mathrm{m}$ deep. A deeper observation reveals a softening beyond this $500-\mu \mathrm{m}$ zone, product of a tempering in the hot affected zone. The affected zone varies between studied steels. In the case of SAE 5130, the tempering reach $8000 \mu \mathrm{m}$ deep, while for steel ASTM 514 grade S, the affected zone reaches $5500 \mu \mathrm{m}$.
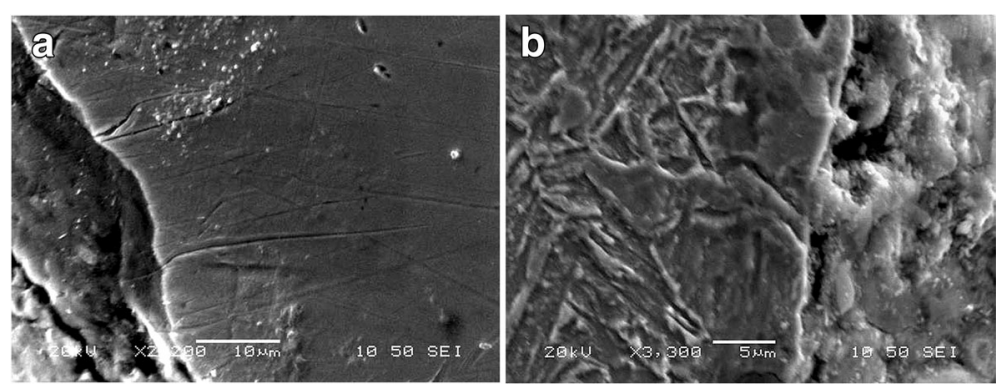

Fig. 6 SEM micrographs of ASTM 514 grade S post-torched steel. a Found defects are different sized micro-cracks into the HAZ, from 15 to $48 \mu \mathrm{m}$. b Microstructural change in the HAZ-bulk interface 


\section{Acknowledgements}

The authors appreciate the collaboration of Minera Sierra Gorda for providing steels, personnel, and equipment and also Company Sorena for cutting by torch and personnel. The work was performed in the Centro de Ingeniería y Tecnología de los Materiales de la Universidad de Antofagasta.

\section{Authors' contributions}

$\mathrm{J}$ and $\mathrm{HO}$ worked experimentally with the obtained samples. $\mathrm{HO}, \mathrm{OF}$, and ZC worked in metallography techniques. HO, JL, OF, and ZC had participated in the analysis and discussion of results. All authors read and approved the final manuscript.

\section{Competing interests}

The authors declare that they have no competing interests.

\section{Publisher's Note}

Springer Nature remains neutral with regard to jurisdictional claims in published maps and institutional affiliations.

\section{Author details}

${ }^{1}$ Centro de Ingeniería y Tecnología de los Materiales Universidad de Antofagasta, Antofagasta, Chile. ${ }^{2}$ Departamento de Ingeniería Mecánica Universidad de Antofagasta, Av. Angamos 601, Antofagasta, Chile. ${ }^{3}$ Minera Sierra Gorda SCM, Antofagasta, Chile. ${ }^{4}$ Instituto de Física de Materiales Tandil, IFIMAT (UNCPBA), Buenos Aires, Argentina. ${ }^{5}$ Centro de Investigaciones en Física e Ingeniería del Centro de la Provincia de Buenos Aires, CIFICEN (UNCPBA-CICPBA-CONICET), Pinto 399, B700GHG Tandil, Argentina.

Received: 11 July 2017 Accepted: 13 July 2017

Published online: 14 August 2017

\section{References}

American Society of Heating (2011). Refrigerating and air-conditioning. Engineers. Environmental Health Committee (EHC) minutes. Winter Meeting January 31, 2011.

Andrés, D., García, T., Cicero, T., Lacalle, R., Álvarez, J., Martín-Meizoso, A. Aldazabal, J., Bannister, A., \& Klimpel, A. (2016). Characterization of heat affected zones produced by thermal cutting processes by means of Small Punch tests. Materials Characterization, 119, 55-64.

ASM (2013). Introduction to Surface Hardening of Steels. ASM handbook, volume 4A, steel heat treating fundamentals and processes. Dossett and G.E. Totten, editors. Heat treating, Vol 4, ASM handbook, ASM International, 1991, p 259-267.

AWS. (1980). Specification for low alloy steel electrodes for flux cored arc welding. American Welting Society, Inc. Miami PL 33125. Appoved by AWS Board of Directors, August 15, 1980.

Bochnowski, W., Leitner, H., Major, L., Ebner, R., \& Major, B. (2003). Primary and secondary carbides in high-speed after conventional heat treatment and laser modification. Material Chemistry and Physics, 81, 503-506.

Christensen, L. J. (1973). Air carbon arc cutting. Welding Journal, 52(12), 782-791.

Cicero, S., García, T., Álvarez, J. A., Klimpel, A., Bannister, A., \& Martín-Meizosod, A. (2017). Fatigue behaviour and BS7608 fatigue classes of steels with thermally cut holes. Journal of Constructional Steel Research, 128, 74-83.

Das, A., \& Abarna, R. (2015). Comparative study of air carbon arc gouging process on Sae 316 stainless steel. International Research Journal of Engineering and Technology (IRJET), 02(02), 1069-1074

Goldberg F. (1978). Influence of thermal cutting and its quality in the fatigue strength of steel. Welding Research Supplement. International Institute I-48372: 392-404.

Gutiérrez J. (2006) Guía de instrucción en fabricación y reparación según curso modelo 7.04 de la omi oficial encargado de la guardia de máquinas, Universidad Austral de Chile. Master Tesis.

Hause, W. O. (1980). What you should know about air carbon arc metal removal. Welding Desing \& Fabrication, 51(1), 52-56.

Hetzner, D. W., \& Van Geertruyden, W. (2008). Crystallography and metallography of carbides in high alloy Steels. Materials Characterization, 59, 825-841.

Hu, J.-f., Yang, J.-g., Hong-yuan, F., Guang-min, L., Yong, Z., \& Wan, X. (2007). Temperature, stress and microstructure in $10 \mathrm{Ni5CrMoV}$ steel plate during airarc cutting process. Computational Materials Science, 38, 631-641.

IS (1979). Recommended practices for air carbon arc gouging and cutting. Indian Standard Institution. WDC 621-791-948-054-4:006-76. IS 8987-1978.
Kyong-Ho, C., \& Lee, C.-H. (2007). Residual stresses and fracture mechanics analysis of a crack in welds of high strength steels. Engineering Fracture Mechanics, 74, 980-994.

Lara, A., Picas, I., \& Casellas, D. (2013). Effect of the cutting process on the fatique behaviour of press hardened and high strength dual phase steels. Journal of Materials Processing Technology, 213, 1908-1919.

Liu, G., Huang, C., Zou, B., Wang, X., \& Liu, Z. (2016). Surface integrity and fatigue performance of $17-4 \mathrm{PH}$ stainless steel after cutting operations. Surface \& Coatings Technology, 307, 182-189.

Luan, Y., Song, N., Bai, Y., Kang, X., \& Li, D. (2010). Effect of solidification rate on the morphology and distribution of eutectic carbides in centrifugal casting highspeed steel rolls. Journal of Materials Processing Technology, 210, 536-541.

Ma, Y., Pingfa, F., Jianfu, Z., Wu, Z., \& Yu, D. (2016). Prediction of surface residual stress after end milling based on cutting force and temperature. Journal of Materials Processing Technology, 235, 41-48.

Marshall, W. J. (1980). Optical radiation levels produced by air carbon arc cutting processes. Welding Journal, 59(3), 43-46.

Michaleris P., Dantzig and Tortorelli D. (1999). Minimization of welding residual stress and distortion in large structures. Welding American Society. Supplement to the Welding Journal, November: 361-366.

Panter, D. (1977). Air carbon arc gouging. Welding Journal, 56(5), 32-37.

Ramaswamy, Murali T. (1989). Heat affected zone studies of thermally cut structural steels. Scholar Archive. Paper 130.

Ridal, E. J. (1977). Preparation for welding by air carbon arc gouging. Welding \& Metal Fabrication 45 (6): 347-353 - 356-362.

Tingaev, A. K., Gubaydulin, R. G., \& llin, R. G. (2016). Study of the effect of thermal cutting on the microstructure and chemical composition of the edges of workpieces made of steel brands S345, S390. International Conference on Industrial Engineering, ICIE 2016. Procedia Engineering, 150, 1783-1790.

U.S. Department of Transportation (1994). Federal Highway Administration, Heataffected zone studies of thermally cut structural steels. Publication No. FHWARD-93-015 December. Research and Development Turner-Fairbank Highway Research Center 6300 Georgetown Pike McLean, Virginia, pp.2101-2296.

Varkey B., Balakrishnan K. and Chandran M. (2013). Experimental analysis of air carbon arc gouging process on SAE 316 stainless steel. Proceedings of International Conference on Materials.

Victor Technologies, Inc. (2013). Air Carbon-Arc Guide Form Number: 89-250-008.

Yang, J., Zheng, Q., Sun, X., Guan, H., \& Hu, Z. (2006). Relative stability of carbides and their effects on the properties of K465 superalloy. Material Science and Engineering A, 429, 341-347.

Yilbas, B. S., \& Arif, A. F. (2011). Laser cutting of steel and thermal stress development. Optics \& Laser Technology, 43, 830-837.

Zhang, J., Wang, X., Paddea, S., \& Zhang, X. (2016). Fatigue crack propagation behaviour in wire+arc additive manufactured Ti-6Al-4V: effects of microstructure and residual stress. Materials and Design, 90, 551-561.

\section{Submit your manuscript to a SpringerOpen ${ }^{\circ}$ journal and benefit from:}

- Convenient online submission

- Rigorous peer review

- Open access: articles freely available online

- High visibility within the field

- Retaining the copyright to your article

Submit your next manuscript at $\gg$ springeropen.com 